Article

\title{
Lactobacilli Strain Mixture Alleviates Bacterial Vaginosis through Antibacterial and Antagonistic Activity in Gardnerella vaginalis-Infected C57BL/6 Mice
}

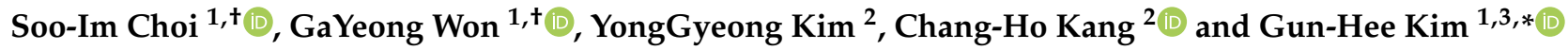 \\ 1 Department of Health Functional New Materials, Duksung Women's University, Seoul 01369, Korea; \\ langdeveu74@duksung.ac.kr (S.-I.C.); gywon04@gmail.com (G.W.) \\ 2 MEDIOGEN, Co., Ltd., Biovalley 1-ro, Jecheon-si 27159, Korea; yongkyung@naver.com (Y.K.); \\ changho-kang@naver.com (C.-H.K.) \\ 3 Department of Food and Nutrition, Duksung Women's University, Seoul 01369, Korea \\ * Correspondence: ghkim@duksung.ac.kr; Tel.: +82-2-901-8496 \\ + These authors contributed equally to this work.
}

check for

updates

Citation: Choi, S.-I.; Won, G.; Kim, Y.; Kang, C.-H.; Kim, G.-H. Lactobacilli Strain Mixture Alleviates Bacterial Vaginosis through Antibacterial and Antagonistic Activity in Gardnerella vaginalis-Infected C57BL/ 6 Mice. Microorganisms 2022, 10, 471. https://doi.org/10.3390/ microorganisms10020471

Academic Editors: Julio Villena and Alex Galanis

Received: 5 January 2022

Accepted: 18 February 2022

Published: 20 February 2022

Publisher's Note: MDPI stays neutral with regard to jurisdictional claims in published maps and institutional affiliations.

Copyright: (c) 2022 by the authors. Licensee MDPI, Basel, Switzerland. This article is an open access article distributed under the terms and conditions of the Creative Commons Attribution (CC BY) license (https:/ / creativecommons.org/licenses/by/ $4.0 /)$.

\begin{abstract}
The present study investigated the anti-bacterial vaginitis (BV) effects of a mixture of five lactobacilli strains (LM5), containing equal amounts of Ligilactobacillus salivarius MG242, Limosilactobacillus fermentum MG901, Lactiplantibacillus plantarum MG989, Lacticaseibacillus paracasei MG4272, and Lacticaseibacillus rhamnosus MG4288), in HeLa cells and Gardnerella vaginalis (GV)-infected BV mice. All strains produced lactic acid and hydrogen peroxide, and were resistant to nonoxynol-9. LM5 significantly inhibited GV growth by $80 \%$, exhibited good adhesion to HeLa cells, and significantly inhibited GV adhesion to these cells. In GV-infected mice, LM5 administered orally at $5 \times 10^{9} \mathrm{CFU} /$ mouse significantly inhibited GV proliferation in the vaginal tract and significantly reduced myeloperoxidase activity, pro-inflammatory cytokine (TNF- $\alpha$, IL- $1 \beta$, and IL-6) levels, and nitric oxide levels in vaginal tissue lysates. Histopathological analysis of vaginal tissues revealed that LM5 markedly suppressed the exfoliation of vaginal epithelial cells. Overall, these results suggest that LM5 might alleviate BV by direct antibacterial and antagonistic activity in vaginal tissues of GV-infected mice.
\end{abstract}

Keywords: lactobacilli strains mixture; Gardnerella vaginalis; bacterial vaginosis; epithelial exfoliation

\section{Introduction}

The vaginal environment of a healthy woman contains over 250 species of bacteria and is maintained by complex interactions or synergies between the host and microbes colonizing the vaginal mucous membrane [1,2]. Disruption of these microbial barriers can lead to a variety of urogenital diseases. Vaginitis is an inflammatory disease characterized by vaginal itching, fever, odor, and abnormal secretions from infected vaginal mucous membranes. This disease is primarily caused by infection or changes in the abnormal microbiota of the vagina [3]. Vaginitis is classified as aerobic vaginitis (AV), bacterial vaginosis (BV), vulvovaginal candidiasis, or trichomonas vaginitis, based on their etiologies [2].

$\mathrm{BV}$ is defined as the clinical symptoms of imbalance accompanied by an increase in vaginal $\mathrm{pH}(\mathrm{pH} \geq 4.5)$, the presence of a white adherent discharge containing exfoliated epithelial cells (clue cells), and a fishy odor [4]. BV is characterized by decreased Lactobacillus counts and excessive growth of multiple anaerobes in the vagina, such as Gardnerella spp., Mycoplasma hominis, and Prevotella spp. [5,6]. AV is associated with more severe inflammatory changes than BV and the presence of predominantly aerobic intestinal commensal bacteria or pathogens, including Streptococcus agalactiae, Enterococcus faecalis, Escherichia coli, and Staphylococcus aureus [7]. Despite the availability of antibiotic treatments for $\mathrm{BV}$, relapse and treatment failure are common due to a failure to restore normal vaginal bacterial microbiota. 
Lactic acid bacteria (LAB) such as Lactobacillus crispatus, L. iners, L. gasseri, and L. jensenii are the most prevalent in vaginal microbiota and play important roles in maintaining a healthy vaginal environment [8]. These bacteria compete with harmful bacteria in the vaginal ecosystem and act as a barrier against vaginal pathogens that cause vaginitis by producing various substances such as lactic acid, hydrogen peroxide, and bacteriocin. Lactobacilli have also been shown to reduce the risk of pregnancy-related and sexually transmitted diseases by increasing vaginal acidity [9].

Recently, probiotics have attracted increasing interest preventing and treating vaginal disorders [10]. Various types of probiotics administered orally with yogurt or as lactobacilli capsules, or by inserting lactobacilli in the form of tampons, have been studied to improve the vaginal environment [11]. Notably, a Lactobacillus mixture (Lacticaseibacillus rhamnosus GR-1 and Limosilactobacillus fermentum RC-14) inhibited BV recurrence [12], and a probiotic mixture (Respecta ${ }^{\circledR}$; L. rhamnosus HN001, Lactobacillus acidophilus GLa-14, and lactoferrin RCXTM) achieved probiotic colonization in the vaginas of healthy women [13]. Although the replacement of antibiotics with probiotics to prevent vaginitis, eliminate pathogens, and improve the vaginal environment is gaining traction, studies on improving the quality of the vaginal environment using Lactobacillus are limited.

Our previous in vivo studies demonstrated that five lactobacilli strains (Lacticaseibacillus paracasei MG4272, L. rhamnosus MG4288, Ligilactobacillus salivarius MG242, L. fermentum MG901, and Lactiplantibacillus plantarum MG989) isolated from the vaginal tract of healthy Korean women have good probiotic properties, such as acid/bile salt-resistance and adhesion (auto-aggregation). Furthermore, these strains demonstrated potential antimicrobial activity against GV or Candida albicans [14-18], and a three-strain mixture (MG242, MG901, and MG989) exhibited anti-BV activity in GV-infected mice [19].

This study was undertaken to evaluate the antagonistic effects of individual strains on GV-infected HeLa cells in vitro and to determine whether a mixture of the five selected species (LM5) promotes vaginitis-improving activity in the GV infected BV mice.

\section{Materials and Methods}

\subsection{Preparation of Lactobacilli Strains and GV}

Five lactobacilli strains (L. salivarius MG242 (KCTC18554P), L. fermentum MG901 (KFCC11651P), L. plantarum MG989 (KFCC11650P), L. paracasei MG4272 (KCTC13822BP), and L. rhamnosus MG4288 (KCTC13823BP)), isolated from a healthy Korean woman's vagina, were supplied by Mediogen Co., Ltd. (Jecheon, Korea). All strains were deposited in the Korean Collection for Type Cultures (KCTC, Daejeon, Korea). Each strain was activated by culture in de Man, Rogosa, and Sharpe (MRS) broth (Difco, Detroit, MI, USA) for $18 \mathrm{~h}$ at $37^{\circ} \mathrm{C}$ [20]. The dried bacterial powder used for in vivo testing was supplied by Mediogen Co., Ltd. The lactobacilli strain mixture (LM5) was prepared by combining the five powdered strains in equal ratios.

G. vaginalis (KCTC5096) was obtained from the KCTC and sub-cultured in modified brain heart infusion (mBHI) broth (Difco, Detroit, MI, USA) supplemented with yeast extract $(1 \%)$, maltose $(0.1 \%)$, glucose $(0.1 \%)$, and horse serum $(10 \%)$ and cultured anaerobically using Anaerocult ${ }^{\circledR}$ A (Merck, Darmstadt, Germany) in a sealed anaerobic jar.

\subsection{Detection of Hydrogen Peroxide $\left(\mathrm{H}_{2} \mathrm{O}_{2}\right)$ Production}

The five strains were activated by culturing in $10 \mathrm{~mL}$ of MRS broth for $24 \mathrm{~h}$ at $37^{\circ} \mathrm{C}$ in a bio-oxygen demand (BOD) incubator. Cultures were centrifuged and filtered to recover culture supernatants, diluted, and the $\mathrm{pH}$ was adjusted to $7-8 . \mathrm{H}_{2} \mathrm{O}_{2}$ contents in the supernatants was quantified using a commercially available kit (DoGenBio Co., Ltd., Seoul, Korea).

\subsection{Analysis of Lactic Acid Production}

Each strain was cultured in $5 \mathrm{~mL}$ MRS broth for $48 \mathrm{~h}$, and the cultures were filtered using a $0.22 \mu \mathrm{m}$ filter. Total lactic acid levels in the filtrates were analyzed by high-performance 
liquid chromatography (HPLC) using a Chiralpak ${ }^{\circledR}$ MA (+) column (reverse phase-type, $4.6 \times 50 \mathrm{~mm}, 5 \mu \mathrm{m}$, Daicel Chemicals Industries Ltd., Tokyo, Japan). The mobile phase containing $2 \mathrm{mM} \mathrm{CuSO}_{4}$ was eluted at a flow rate of $1.0 \mathrm{~mL} / \mathrm{min}$, and the sample injection volume was $10 \mu \mathrm{L}$. The effluent was monitored at $254 \mathrm{~nm}$ using a UV detector. L-(+)- and D-(-)-lactic acid (Sigma-Aldrich, St. Louis, MO, USA) were used as standard solutions.

\subsection{Resistance to Spermicide}

The five lactobacilli strains were tested for spermicide resistance by culturing them on MRS agar containing varying concentrations of nonoxynol-9 (N-9, ab143673, Abcam, Cambridge, MA, USA) as described previously with minor modifications [21]. N-9 was diluted to concentrations of $0,6.4,12.8$, and $25.6 \%(v / v)$, respectively, with MRS broth ( $\mathrm{pH}$ 6.5). Cultures were washed twice in phosphate-buffered saline (PBS, $\mathrm{pH}$ 7.1) and resuspended at $1 \times 10^{7}$ cells $/ \mathrm{mL}$. The suspension $(50 \mu \mathrm{L})$ was added to $3 \mathrm{~mL}$ of medium alone (control) or medium with $\mathrm{N}-9$, mixed thoroughly, and incubated for $18 \mathrm{~h}$ in a $5 \% \mathrm{CO}_{2}$ atmosphere at $37^{\circ} \mathrm{C}$. Growth was assessed based on visual examinations of turbidity.

\subsection{Antibacterial Effects of Lactobacilli Strains on GV Growth}

The anti-GV activities of lactobacillus strains were evaluated using cell-free culture supernatants (CFS) [19]. To prepare the CFS, the lactobacilli strains were individually cultured in MRS broth $(10 \mathrm{~mL})$ for $24 \mathrm{~h}$ at $37^{\circ} \mathrm{C}$ and centrifuged at $4000 \times \mathrm{g}$ for $10 \mathrm{~min}$. The supernatants were filtered through a $0.2 \mu \mathrm{m}$ membrane filter to remove debris.

GV $\left(1 \times 10^{6} \mathrm{CFU}\right)$ was incubated in an $\mathrm{mBHI}$ medium containing $10 \%$ of each CFS and cultured at $37^{\circ} \mathrm{C}$ for $36 \mathrm{~h}$ under anaerobic conditions. Viable GV numbers were then determined by diluting and plating on BHI agar containing $5 \%$ horse blood at $37^{\circ} \mathrm{C}$ for $24 \mathrm{~h}$ under anaerobic conditions and counting CFUs.

\subsection{The Cytotoxic Effect of Lactobacilli Strains on HeLa Cells}

HeLa cells (KCLB10002) were obtained from the Korea Cell Line Bank (KCLB, Seoul, Korea). The cytotoxic effect of lactobacillus strains on HeLa cells was evaluated using an MTT assay using the CFS of each strain. Briefly, HeLa cells were cultured in RPMI 1640 supplemented with $10 \%$ fetal bovine serum (FBS) (Gibco, Grand Island, NY, USA) and incubated in a $5 \% \mathrm{CO}_{2}$ atmosphere at $37^{\circ} \mathrm{C}$ for 2 days until confluent. HeLa cell suspensions were seeded at a density of $5 \times 10^{4}$ cells $/ \mathrm{mL}$ in 24-well plates and incubated with CFS $(100 \mu \mathrm{L})$ for $18 \mathrm{~h}$ at $37^{\circ} \mathrm{C}$ in a $5 \% \mathrm{CO}_{2}$ atmosphere. Non-treated HeLa cells were used as the controls.

\subsection{Adhesion Ability of Lactobacilli Strains to HeLa Cells}

The ability of the strains to adhere to HeLa cells was assessed [22]. HeLa cells were cultured in RPMI 1640 supplemented with 10\% FBS and incubated in a $5 \% \mathrm{CO}_{2}$ atmosphere at $37^{\circ} \mathrm{C}$ for 2 days until confluence. HeLa cell suspensions were seeded at $5 \times 10^{4}$ cells $/ \mathrm{mL}$ in 24-well plates for $18 \mathrm{~h}$ at $37^{\circ} \mathrm{C}$ in $5 \% \mathrm{CO}_{2}$ and washed twice with sterile PBS.

Lactobacilli strains were prepared by culturing in MRS broth at $37^{\circ} \mathrm{C}$ for $18 \mathrm{~h}$. Cultures were centrifuged at $4000 \times \mathrm{g}$ for $10 \mathrm{~min}$ at $4^{\circ} \mathrm{C}$ and washed twice with PBS (pH 7.4). The pellets were resuspended in RPMI 1640 medium at a density of $2 \times 10^{8} \mathrm{CFU} / \mathrm{mL}$. Each strain suspension $(500 \mu \mathrm{L})$ was added to each well and incubated for $1 \mathrm{~h}$ at $37^{\circ} \mathrm{C}$ in a $10 \%$ $\mathrm{CO}_{2}$ atmosphere. After incubation, the cells were washed three times with sterile PBS and detached with sterile distilled water $(200 \mu \mathrm{L})$. The cells were then diluted and plated onto MRS agar, cultured at $37^{\circ} \mathrm{C}$ for $24 \mathrm{~h}$ under anaerobic conditions, and the number of viable lactobacilli strains was determined by counting the colonies.

\subsection{Antagonistic Activity of Lactobacilli Strains against GV Adhesion to HeLa Cells}

The antagonistic effects of each strain on GV adhesion to HeLa cells were assessed as previously described [22]. Prior to infection, HeLa cells were cultured at a density of $5 \times 10^{4}$ cells $/ \mathrm{mL}$ in 24-well plates, washed twice with sterile PBS, and replaced with 
$500 \mu \mathrm{L}$ of fresh culture medium. GV was cultured in $\mathrm{mBHI}$ medium at $37^{\circ} \mathrm{C}$ for $18 \mathrm{~h}$ under anaerobic conditions. The pellets recovered by centrifugation $\left(4000 \times g\right.$ for $10 \mathrm{~min}$ at $\left.4{ }^{\circ} \mathrm{C}\right)$ were washed twice with PBS (pH 7.4) and resuspended in RPMI 1640 medium. Lactobacilli strains were prepared by culturing in MRS broth at $37^{\circ} \mathrm{C}$ for $18 \mathrm{~h}$. The recovered pellets were resuspended in RPMI 1640 medium in the same method.

Each lactobacillus strain $\left(250 \mu \mathrm{L}, 1 \times 10^{8} \mathrm{CFU} / \mathrm{mL}\right)$ or GV $\left(250 \mu \mathrm{L}, 1 \times 10^{8} \mathrm{CFU} / \mathrm{mL}\right)$ suspended in culture media was added to the wells and incubated for $1 \mathrm{~h}$. Then, the cells were washed three times with sterile PBS and detached with sterile distilled water $(200 \mu \mathrm{L})$. The cells were diluted and plated on Columbia Blood (CB) agar to measure the quantity of viable GV. After incubating at $37^{\circ} \mathrm{C}$ for $24 \mathrm{~h}$ under anaerobic conditions, the bacterial colonies were counted.

\subsection{GV-Infected BV Mice Model and LM5 Administration}

C57BL / 6 female mice (5 weeks, weighing 19-22 g) were obtained from Orientbio Co., (Seongnam, Korea). The mice were housed in cages under climate-controlled conditions $\left(50 \% \pm 10 \%\right.$ humidity and $\left.20-22{ }^{\circ} \mathrm{C}\right)$, fed standard laboratory chow (No. EEGJ36060, Furina Inc., Seongnam, Korea), and allowed water ad libitum. Animal experiments were approved by the Institutional Animal Care and Use Committee (IACUC) of Duksung Women's University (No. 2019-011-001). All efforts were made to minimize animal suffering.

Mice were randomly allocated to the following four groups ( $n=6 /$ group): (1) a nontreated normal control group (NOR), (2) a BV-infected non-treated control group (CON), (3) a BV-infected LM5A (5 × $10^{8} \mathrm{CFU} /$ mouse)-treated group, and (4) a BV-infected LM5B $\left(5 \times 10^{9} \mathrm{CFU} /\right.$ mouse)-treated group. To induce BV by GV infection, all mice were injected intraperitoneally with $\beta$-estradiol-3-benzoate $(0.5 \mathrm{mg} / 100 \mathrm{~mL}$ in olive oil) 3 days before and on the day of GV inoculation, except for the NOR group. After $3 \mathrm{~h}$, the mice were inoculated vaginally with GV $\left(5 \times 10^{6} \mathrm{CFU} / 20 \mu \mathrm{L}\right)$ dissolved in sterile PBS, as previously described $[23,24]$. LM5 powder was dissolved in sterile PBS and orally administered once daily for 2 weeks following GV induction. The NOR and CON groups were treated with saline instead of the lactobacilli strains. The dosages of lactobacilli strains were determined based on our preliminary in vitro studies and a previous study by Daniel et al. [25]. The mice were sacrificed to harvest the vaginas after completing the experiment. Excised vaginal tissues were washed and stored at $-80^{\circ} \mathrm{C}$ until analysis.

\subsection{GV Proliferation in Vaginal Tissues}

Excised vaginal tissues were flushed with $50 \mu \mathrm{L}$ of sterile PBS, pipetted up and down 10 times, and then recovered in a sterile Eppendorf tube. The vaginal washings were diluted by 10 -fold serial dilution with PBS and then plated on GV-selective media (Thermo Scientific $^{\mathrm{TM}}$, Waltham, MA, USA). GV colonies were counted, and the results were presented as CFU per $1 \mathrm{~mL}$ of vaginal fluid.

\subsection{Myeloperoxidase (MPO) Activity in Vaginal Lysates}

MPO activity was measured in vaginal tissue lysates. Briefly, vaginal tissues were homogenized in RIPA buffer (Sigma-Aldrich, St. Louis, MO, USA), sonicated, and centrifuged at 12,000 rpm for $20 \mathrm{~min}$ at $4{ }^{\circ} \mathrm{C}$. Protein levels were measured using the Bradford method (Bio-Rad, Hercules, CA, USA). MPO activity was determined using a commercial ELISA kit (Sigma-Aldrich, St. Louis, MO, USA).

\subsection{Pro-Inflammatory Cytokines Levels in Vaginal Tissue Lysates}

The levels of inflammatory cytokines were measured in the supernatants collected from vaginal tissue lysates. Briefly, vaginal tissue lysates were homogenized in ice-cold RIPA lysis buffer containing 1\% protease inhibitor cocktail and 1\% phosphatase inhibitor cocktail. Lysates were centrifuged for $20 \mathrm{~min}$ at $4{ }^{\circ} \mathrm{C}$, and the protein levels in the supernatants were quantified using the Bradford method. The levels of TNF- $\alpha$, IL- 6 , IL- $1 \beta$, 
and nitric oxide (NO) in supernatants were measured using commercial ELISA kits (R\&D Systems, Minneapolis, MN, USA).

\subsection{Histopathological Examination}

The effect of LM5 on GV-infected BV mice was evaluated by analyzing the histopathological changes in vaginal tissues. Briefly, tissues were fixed in $10 \%$ formalin for at least $24 \mathrm{~h}$, embedded in paraffin, sectioned at $5 \mu \mathrm{m}$, stained with hematoxylin and eosin (H\&E), and examined under a microscope. Changes in the vaginal tissue following BV induction were evaluated by histopathological observation. The degree of exfoliation and inflammation of vaginal epithelial cells was scored from 0 to 3 as follows: 0 , normal; 1 , minimal; 2, moderate; 3, marked [23]. The vaginal epithelial thickness was also measured at a diameter of 30 sites randomly selected using a $40 \times$ magnification of an optical microscope (BX51, Olympus, Japan) equipped with a camera (300MI CMOS, Aptina, CA, USA) and an image analysis system (Scope Eye, Samkyung, Korea). A board-certified toxicological pathologist performed all the histological evaluation procedures blindly.

\subsection{Statistical Analysis}

All data are expressed as the mean \pm standard deviation (SD) of experiments performed in triplicate. The analysis was conducted using SPSS version 22 (IBM Corp., Armonk, NY, USA). Statistical significance was determined by one-way analysis of variance (ANOVA) followed by post hoc analysis using Dunnett's multiple comparison tests. Statistical significance was set at $p<0.05$.

\section{Results}

\subsection{Lactic Acid and $\mathrm{H}_{2} \mathrm{O}_{2}$ Production}

The production of lactic acid and $\mathrm{H}_{2} \mathrm{O}_{2}$ was evaluated in the culture supernatants of the five selected strains. After incubation, the $\mathrm{pH}$ of the culture media of MG242, MG989, MG4272, and MG4288, but not MG901, was in the range of $3.77 \pm 0.019$ to $3.83 \pm 0.003$. All strains produced $\mathrm{H}_{2} \mathrm{O}_{2}$, with MG901 producing the most. Lactic acid production in the culture supernatants was measured using the HPLC-UV method. All strains produced $\mathrm{D}(-)$ - and L(+)-lactate, and total lactic acid production was highest for MG4272, followed by MG242 strain (Table 1).

Table 1. Lactic acid and $\mathrm{H}_{2} \mathrm{O}_{2}$ production and Nonoxynol-9 (N-9) susceptibility of lactobacilli strains.

\begin{tabular}{|c|c|c|c|c|}
\hline Strains & $\mathrm{pH}$ & $\begin{array}{c}\mathrm{H}_{2} \mathrm{O}_{2} \text { Content } \\
(\mathrm{g} / \mathrm{L})\end{array}$ & $\begin{array}{l}\text { Lactic Acid Content } \\
D(-)+L(+)(g / L)\end{array}$ & $\begin{array}{c}\text { N-9 Susceptibility } \\
(+/-)\end{array}$ \\
\hline Ligilactobacillus salivarius MG242 & $3.77 \pm 0.02$ & $1.23 \pm 0.00$ & $17.44 \pm 1.1$ & - \\
\hline Limosilactobacillus fermentum MG901 & $4.32 \pm 0.02$ & $1.93 \pm 0.08$ & $11.83 \pm 1.8$ & - \\
\hline Lactiplantibacillus plantarum MG989 & $3.76 \pm 0.01$ & $0.96 \pm 0.09$ & $11.83 \pm 0.9$ & - \\
\hline Lacticaseibacillus paracasei MG4272 & $3.78 \pm 0.01$ & $0.80 \pm 0.06$ & $18.76 \pm 2.4$ & - \\
\hline Lacticaseibacillus rhamnosus MG4288 & $3.83 \pm 0.01$ & $0.78 \pm 0.05$ & $15.43 \pm 1.0$ & - \\
\hline
\end{tabular}

\subsection{Nonoxynol-9 Susceptibility}

As spermicides are widely used, it is essential to identify probiotic strains that can tolerate spermicidal agents. N-9 is a safe contraceptive spermicide commonly present in commercialized spermicides at a concentration of 5\% [26]. N-9 is also a nonionic detergent associated with changes in commensal vaginal microflora and is particularly toxic to $\mathrm{H}_{2} \mathrm{O}_{2}-$ producing lactobacilli strains $[27,28]$. We assessed whether lactobacilli strains were resistant to N-9. The maximum inhibitory concentration (MIC) of all five strains to N-9 was $>25.6 \%$, indicating resistance (-) to N-9. 


\subsection{Antibacterial Effect of Lactobacilli Strains against GV}

GV is the most dominant bacterium in the vaginal ecosystem of patients with BV and is known to be sufficient to induce the clinical symptoms of BV and related health complications $[29,30]$. We evaluated the in vitro antimicrobial activity of CFS obtained from five individual strains and LM5 against GV. As shown in Figure 1, the survival rate of GV significantly decreased after treatment for $24 \mathrm{~h}$ with all CFS. Among the single strains, MG4288 had the highest inhibition rate of $60 \%$. In addition, the survival rate against GV was significantly higher in LM5 than in all individual strains and exhibited the highest antibacterial activity of $75 \%$ against GV.

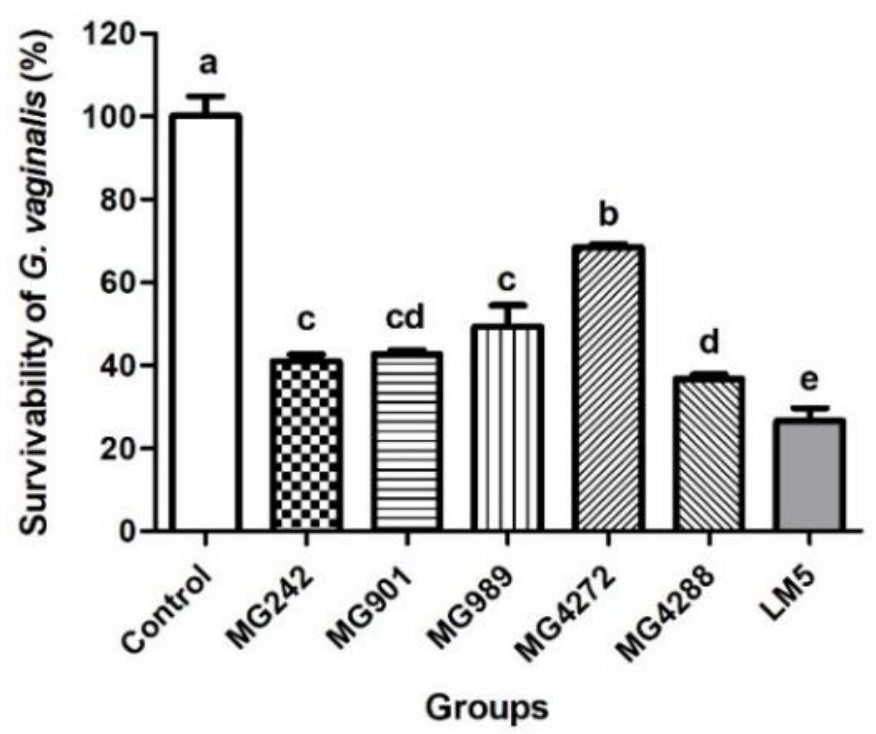

Figure 1. Survival rates of Gardnerella vaginalis (GV) alone or when treated with cell-free supernatants (CFS) of lactobacilli strains. GV was inoculated into BHI broth added with MRS broth (control) or the CFS of each of the strains and cultured for $24 \mathrm{~h}$ at $37^{\circ} \mathrm{C}$. LM5: mixture of five strains in the same ratio. Results are presented as mean $\pm \operatorname{SD}(n=3)$. Different letters indicate significant differences between means at $p<0.05$ by Duncan's multiple range test.

\subsection{Antagonistic Effect of Lactobacilli Strains on GV Adhesion to HeLa Cells}

The ability of lactobacilli to adhere to vaginal epithelial cells is important for maintaining the vaginal environment by preventing pathogen adhesion, removing amine compounds, maintaining acidity, and producing antibacterial substances such as bacteriocins $[31,32]$.

This study confirmed the non-cytotoxic effect of the five strains and LM5 by treating HeLa cells with CFS (Figure 2A). Next, we confirmed the ability of the five strains to adhere to HeLa cells. All strains showed relatively high adhesion $(>7.0 \log \mathrm{CFU} / \mathrm{mL})$, except for MG4272. MG4288 showed the highest adhesion at $7.7 \log$ CFU/mL (Figure 2B).

In addition, the mechanism responsible for anti-BV activity was investigated by evaluating the antagonistic effect of lactobacilli strains and LM5 on GV adhesion. Each strain and LM5 inhibited GV adhesion by an average of $>35 \%$ compared to GV-treated cells (CON). MG901, MG242, MG989, and LM5 reduced GV counts by $>40 \%$ (Figure 2C). 

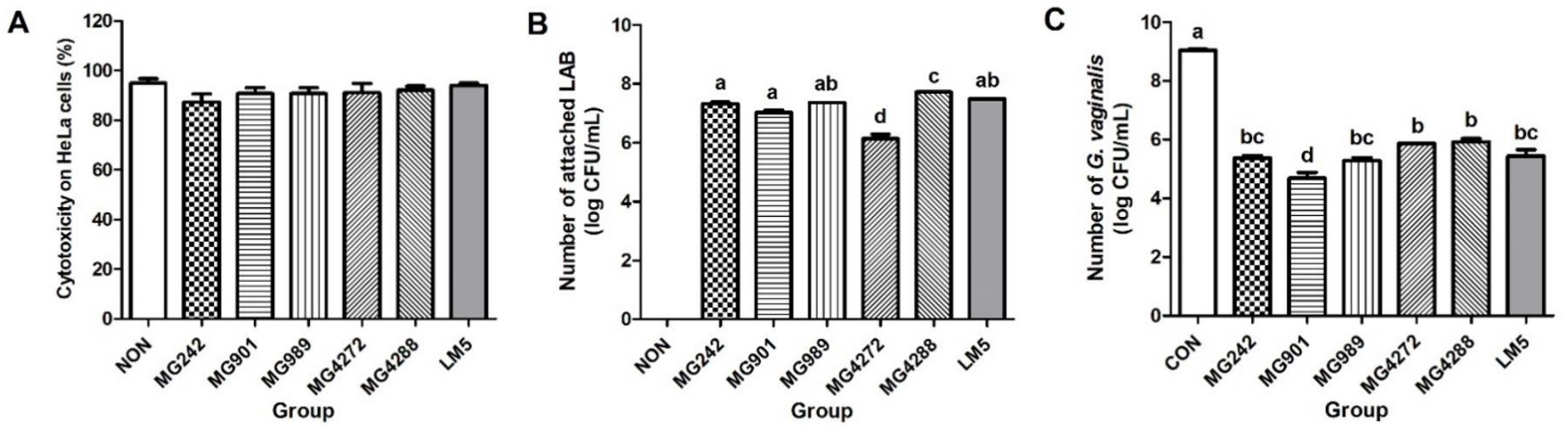

Figure 2. Antagonistic activity of lactobacilli strains against GV-adhesion to HeLa cells: (A) cytotoxic effects of cell-free culture supernatant (CFS) of lactobacilli on HeLa cells, (B) adhesion abilities of lactobacilli strains to HeLa cells, and (C) antagonistic effect of lactobacillus strains on GV adhesion to HeLa cells. NON: HeLa cells treated only with culture media, CON: HeLa cells treated only with GV without lactobacilli strains, LM5: mixture of five strains in the same ratio. Results are presented as mean \pm SD $(n=3)$. Different letters indicate a significant difference between means at $p<0.05$ by Duncan's multiple range test.

\subsection{Inhibitory Effect of LM5 on Vaginal GV Proliferation in GV-Infected BV Mice}

Mice infected with GV exhibited BV-like characteristics, such as vaginal epithelial detachment, sialidase activity in vaginal fluid, mucus decomposition, and uterine infection [23]. In this study, BV was induced in mice by vaginal injection of GV $\left(5 \times 10^{6} \mathrm{CFU}\right.$ suspension), and, subsequently, infection was confirmed by the presence of intravaginal opaque mucus. The GV proliferation inhibitory activities of LM5A and LM5B on vaginal epithelial cells were evaluated by assessing the degree of colonization using the vaginal wash solution.

The collected vaginal wash solutions were diluted and plated on a GV-selective medium. GV cells counts were markedly higher in the BV-infected CON group $(6.84 \pm 0.43 \log \mathrm{CFU} / \mathrm{mL})$ than in the NOR group. LM5A at $5 \times 10^{8} \mathrm{CFU}$ did not significantly reduce GV cell counts versus the CON group. On the other hand, LM5B at $5 \times 10^{9}$ CFU significantly reduced GV growth to $5.15 \pm 0.90 \log \mathrm{CFU} / \mathrm{mL}$ (Figure 3).

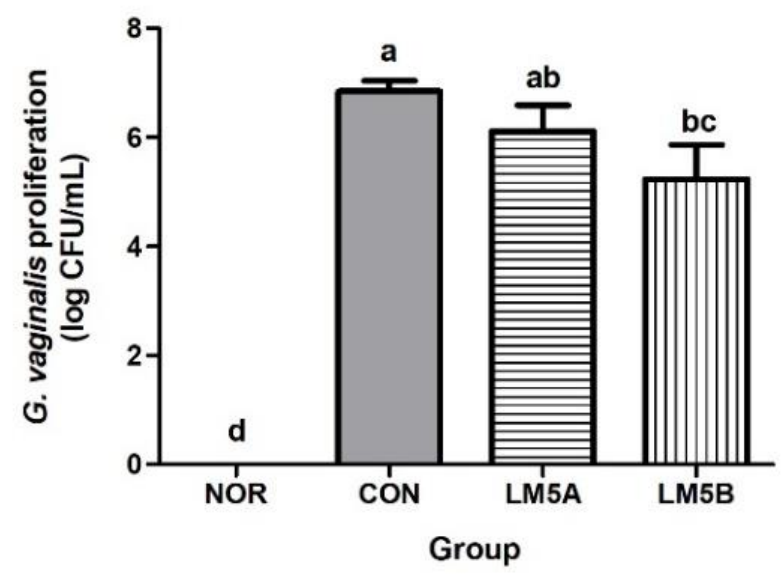

Figure 3. Effect of the lactobacilli strains mixture (LM5) on GV proliferation in GV-infected BV mice. Mice were fed with or without LM5A $\left(5 \times 10^{8} \mathrm{CFU} /\right.$ mouse $)$ or LM5B $\left(5 \times 10^{9} \mathrm{CFU} /\right.$ mouse $)$ for 2 weeks starting the day after GV inoculation. NOR: normal mice without GV infection, CON: GV infection mice without lactobacillus mixture administration. GV proliferation in mice was assessed using GV-selective agar and vaginal washes. Results are presented as mean $\pm \operatorname{SD}(n=6)$. Different letters indicate a significant difference between means at $p<0.05$ by Duncan's multiple range test. 


\subsection{Inhibitory Effect of LM5 on MPO Activity in Vaginal Tissue}

MPO is a lysosomal protein that is highly expressed in neutrophils and plays a role in antimicrobial actions resulting from neutrophil stimulation [33]. In this study, MPO activity was measured as a biochemical index that reflects the degree of neutrophil infiltration in the vaginal tissues of GV-infected mice [34].

MPO activity was measured using vaginal tissue lysates. MPO activity in the CON group $(1.01 \pm 0.07 \mathrm{nM} / \mathrm{min} / \mathrm{mg})$ was twofold higher than in the NOR group $(0.44 \pm 0.13 \mathrm{nM} / \mathrm{min} / \mathrm{mg}$ ) (Figure $4 \mathrm{~A})$. However, MPO activities in the LM5A and B groups were significantly lower than in the CON group and were lower in the LM5B group $(0.54 \mathrm{~nm} \pm 0.04 \mathrm{nM} / \mathrm{min} / \mathrm{mg})$ than in the LM5A group $(0.69 \mathrm{~nm} \pm 0.10 \mathrm{nM} / \mathrm{min} / \mathrm{mg})$.
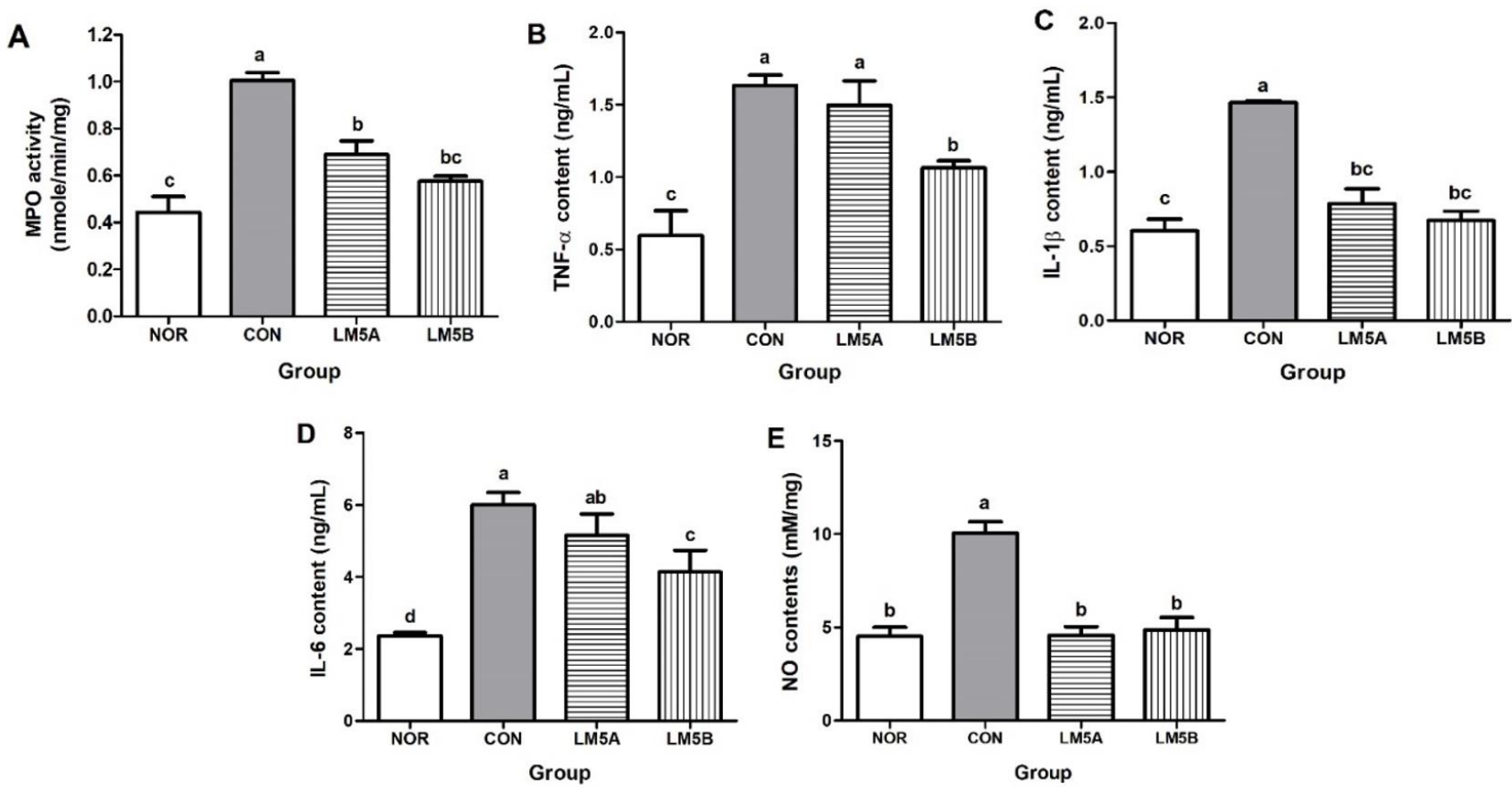

Figure 4. Effect of the lactobacilli strains mixture (LM5) administration on MPO activity (A), proinflammatory cytokines (B-D), and nitric oxide (NO) production (E) in GV-infected BV mice. Mice were fed with or without the LM5A $\left(5 \times 10^{8} \mathrm{CFU} /\right.$ mouse $)$ or LM5B $\left(5 \times 10^{9} \mathrm{CFU} / \mathrm{mouse}\right)$ from the day after GV was inoculated for 2 weeks. MPO activity, and proinflammatory cytokine and NO levels were measured using vaginal tissue lysate. NOR: normal mice without GV infection, CON: GV infection mice without lactobacillus mixture administration. Results are presented as mean \pm SD $(n=6)$. Different letters indicate a significant difference between means at $p<0.05$ by Duncan's multiple range test.

\subsection{Inhibitory Effect of LM5 on Proinflammatory Cytokines Production in Vaginal Tissue}

The anti-inflammatory activity of LM5 in GV-infected BV mice was investigated by measuring the levels of inflammatory cytokine in vaginal tissue lysates. TNF- $\alpha$, IL- $1 \beta$, IL-6, and NO levels in the CON group were significantly increased by more than twofold compared to those in the NOR group. NO levels in the LM5A and B groups were similar to those observed in the NOR group. On the other hand, TNF- $\alpha$ and IL-6 levels were significantly reduced in the LM5B group (Figure 4B-E).

\subsection{Histopathological Analysis on Vaginal Tissues of GV-Infected Mice}

$\mathrm{BV}$ is characterized by the production of white secretions containing clue cells (exfoliated epithelial cells) and Gram-positive, rod-shaped bacteria attached to the surface of vaginal tissue [35]. In this study, the extracted vaginal tissues were washed and fixed, and tissue changes were confirmed by H\&E staining. 
As shown in Figure 5A, epithelial cell exfoliation was clearly observed in the vaginal tissues of GV-infected mice. The CON group showed more severe epithelial cell exfoliation than the NOR group. On the other hand, the LM5A and B groups showed considerably less exfoliation. A few eosinophils were observed in the dermis of some samples, but they were within the normal range, and no group showed inflammatory cell infiltration of vaginal tissue epithelial cells. In addition, no significant intergroup differences in epithelial tissue thickness were observed.

A

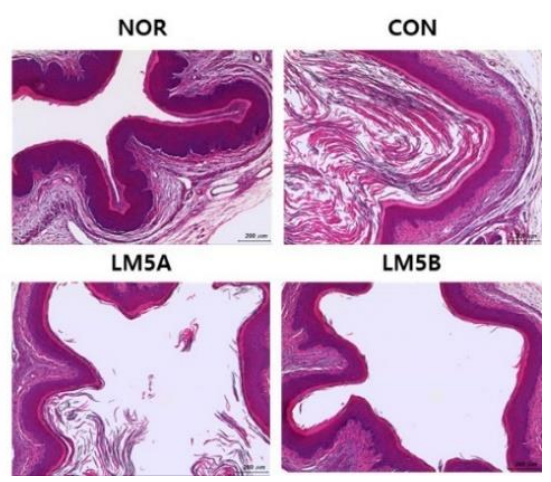

B

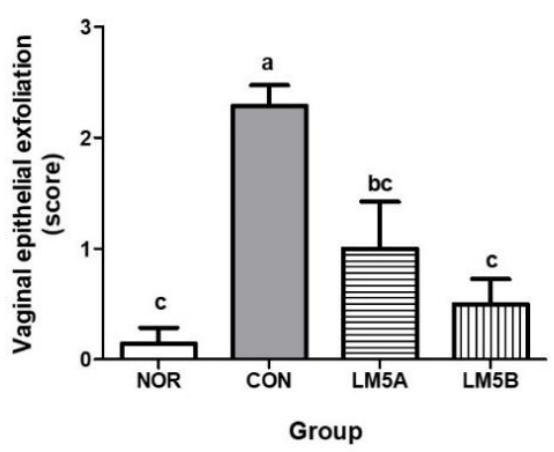

Figure 5. Histopathological analysis of vaginal tissues of GV-infected BV mice. (A) representative histopathological image of vaginal tissue, (B) vaginal epithelial exfoliation score. Mice were fed with or without LM5A $\left(5 \times 10^{8} \mathrm{CFU} /\right.$ mouse) or LM5B $\left(5 \times 10^{9} \mathrm{CFU} /\right.$ mouse $)$ for 2 weeks starting the day after GV inoculation. NOR: normal mice without GV infection, CON: GV infection mice without lactobacillus mixture administration. After completing the experiment, vaginal tissues were fixed, embedded in paraffin, sectioned, and stained with hematoxylin and eosin (H\&E). Results are presented as mean $\pm \mathrm{SD}(n=6)$. Different letters indicate a significant difference between means at $p<0.05$ by Duncan's multiple range test.

The vaginal epithelial exfoliation score was significantly higher in the CON group $(2.28 \pm 0.49)$ than in the NOR group. The exfoliation score of the LM5B group was not significantly lower than that of the NOR group (Figure 5B).

\section{Discussion}

A lack of lactobacilli in the vaginal microflora results in the microbial environment in the vagina becoming less acidic, which favors the recurrence of BV due to the proliferation of anaerobic bacteria [36]. Although the underlying reasons for the high recurrence rate of BV are not clear [37], recurrent BV after antibiotic treatment is known to be caused by an increase in vaginal $\mathrm{pH}$, increases in residual clue cells, abnormal anaerobic bacteria, and lactobacilli deficiency $[10,38]$. Therefore, improving the vaginal environment by maintaining vaginal acidity and inhibiting the proliferation of excessive anaerobic bacteria is important to prevent the recurrence of $\mathrm{BV}$.

The mechanisms underlying the antibacterial effects of lactobacilli strains on vaginal bacterial pathogens involve hydrogen peroxide, lactic acid, bacteriocin-like molecules, and antibacterial molecules [39]. Kumherová et al. [40] reported that the $\mathrm{H}_{2} \mathrm{O}_{2}$ production of $L$. rhamnosus and L. fermentum strains were $0.7 \mathrm{~g} / \mathrm{L}$ on average. However, in this study, the $\mathrm{H}_{2} \mathrm{O}_{2}$ production of each strain was $0.78-1.93 \mathrm{~g} / \mathrm{L}$, indicating superior production capacity. In addition, an in vitro study showed the antibacterial activity of the individual strains and mixtures against GV. LM5 significantly reduced survival rate of GV compared to that of the CFS of individual strains (Figure 1). Atassi et al. [41] reported that the survival rates of GV and Prevotella bivia were significantly reduced by co-treatment with culture supernatants of L. acidophilus, L. jensenii, L. gasseri, and L. crispatus isolated from healthy women. Sethi et al. [42] showed that LAB that produces hydrogen peroxide effectively inhibited GV growth. Atassi et al. [43] reported that the cooperative actions of lactic acid and hydrogen peroxide in the CFS of lactobacilli exhibited enhanced elimination of 
vaginitis-related pathogens. In the present study, the high lactic acid and $\mathrm{H}_{2} \mathrm{O}_{2}$ production abilities of the five strains corresponded to antibacterial activities against $G \mathrm{~V}$, and our results suggested that the lactobacilli strain mixture more effectively inhibited GV growth than individual strains.

Lactobacillus ingested orally can pass through the stomach and intestines and naturally migrate through the circumference of the vaginal inlet, thereby addressing vaginal microbiota imbalance [44]. The adhesion of lactobacilli to vaginal epithelial tissue is the first step toward forming a barrier that prevents undesirable microbial colonization and is the important property of probiotics intended for vaginal surface colonization $[45,46]$. Coudeyras et al. [47] reported the antagonistic activity of L. rhamnosus strain (Lcr35) against vaginal pathogens in cervical cells. Qian et al. [48] reported that three Lactobacillus strains ( $L$. delbrueckii DM8909, L. plantarum ATCC14917, and L. plantarum ZX27) inhibited GV growth, adhesion, and biofilm formation in vitro. Similar to the results from previous studies, this study showed that all strains and the mixture adhered well to HeLa cells and exhibited potential antagonistic activity against GV in HeLa cells.

Vaginal anaerobic bacteria destroy vaginal mucosa cells by secreting various enzymes such as sialidase and proline iminopeptidase, and gray-white vaginal secretions are produced when vaginal mucosa cells are eliminated [10]. GV has excellent biofilm formation ability and promotes the adhesion of other BV-related pathogens [39]. Gilbert et al. [23] reported that $\mathrm{GV}$ inoculated into the vagina of mice survived for at least three days and that colonizing GV moved to the uterine horns.

In a preliminary study, we confirmed that the five-strain combination used in the present study had more significant anti-BV activity than any individual strain or a mixture of the previous three strains (Supplementary Figures S1 and S2). In this study, the BV improvement effect of a mixture of five strains (LM5) was investigated by administering two concentrations $\left(5 \times 10^{8} \mathrm{CFU} /\right.$ mouse and $\left.5 \times 10^{9} \mathrm{CFU} / \mathrm{mouse}\right)$ in GV-infected mice. The degree of BV induction in GV-infected mice was confirmed by assessing the survival rate of GV, inflammation, and by histological examination of vaginal tissues. In the vaginas of the BV mice, the viscosity of white vaginal fluid was high, and the number of vaginal GV colonies was significantly higher than in the NOR group. However, this GV increase in the CON group was reduced by approximately $29 \%$ in the LM5B group. Consistent with our findings, Daniel et al. [24] reported that L. fermentum L23 ameliorated BV by inhibiting GV growth in vaginally-infected mice. These results are considered to be due to the antibacterial and antagonistic activities of LM5 against GV, as shown in the HeLa cells in vitro.

Clinical studies have shown that GV is present on the tissue surfaces of vaginal specimens from women with BV but without apparent signs of inflammation [49,50]. Clinically, BV is regarded to be a non-inflammatory condition because it is not associated with swelling of vaginal tissues or increased neutrophils in the cervicovaginal space [51,52]. Muzny et al. [53] reported that G. vaginalis and P. bivia are abundant in women with BV inflammation but they do not induce a robust inflammatory response in vaginal epithelial cells. However, several studies have reported that pro-inflammatory cytokines such as TNF- $\alpha$, IL-1 $\beta$, IL-6, and IL-8 are elevated in vaginal samples of women with BV $[54,55]$. Wasiela [56] showed that elevated pro-inflammatory cytokine levels in the vaginas of patient with BV correlated with BV severity in certain cases.

In this study, LM5 administration significantly reduced MPO activity and pro-inflammatory cytokine and NO levels caused by GV inoculation in mice. Santos et al. [57] reported that the anti-inflammatory effects of L. plantarum 59 and L. fermentum 137 were due to inhibition of the NF-kB pathway in HeLa cells treated with GV or Candida albicans. Similarly, Joo et al. [22] reported that L. johnsonii HY7042 inhibited BV by regulating NF- $\kappa$ B activation and suppressing the expression of pro-inflammatory cytokines. These results suggest that LM5 administration may suppress inflammatory responses by inhibiting the production of inflammatory cytokines in GV-infected vaginas. 
Normally, exfoliation removes adherent pathogens and acts as a defense mechanism against pathogens in the vagina. However, excessive exfoliation provides access to underlying tissue, facilitates the establishment of BV-related bacteria, and increases the risk of secondary infection. GV has been shown to interact with vaginal epithelial cells in culture, and thus bacterial-coated clue cells are a qualitative diagnostic feature of BV [58]. Gilbert et al. [23] established increased epithelial thickness and exfoliation of epithelial cells without an inflammatory response in GV-infected mice.

In the present study, the exfoliation of vaginal epithelial cells was clearly observed in GV-infected BV mice, and LM5 administration significantly suppressed this exfoliation. However, no significant tissue inflammation, swelling, or polymorphic nuclear cell infiltration was observed, as previously discussed. Therefore, the lactobacilli strain mixture might improve BV symptoms by reducing the exfoliation of vaginal epithelial tissue caused by GV infection. However, since there is a limitation in that the experiment was conducted using only a single strain of $G$. vaginalis, further studies to confirm the antibacterial efficacy against various pathogens may be necessary.

\section{Conclusions}

We investigated the effect of a mixture of five probiotic strains isolated from the vaginas of Korean women on BV symptoms in a GV-infected mouse model. Administration of a mixture of these five strains significantly reduced the production of vaginal inflammatory substances in the BV mice. In addition, its direct antibacterial effect and antagonistic activity against GV in vaginal tissue effectively inhibited the exfoliation of vaginal epithelial cells. Therefore, these findings suggest that LM5 has potential use as a probiotic candidate to prevent or alleviate the symptoms of BV.

Supplementary Materials: The following supporting information can be downloaded at: https: //www.mdpi.com/article/10.3390/microorganisms10020471/s1, Figure S1: Effect of individual lactobacilli strains administration in GV-infected BV mice; Figure S2: Effect of lactobacilli strains mixture administration in GV-infection BV mice.

Author Contributions: Conceptualization and methodology, S.-I.C. and C.-H.K.; Investigation, S.I.C., G.W., and Y.K.; Writing—original draft preparation, S.-I.C. and G.W.; writing-review and editing, G.-H.K. All authors have read and agreed to the published version of the manuscript.

Funding: This research was financially supported by the Ministry of Small and Medium-sized Enterprises (SMEs) and Startups (MSS), Korea, under the "Regional Star-Enterprise Development Program" funded by the Korea Institute for Advancement of Technology (KIAT) (Project No. P0010059).

Institutional Review Board Statement: Not applicable.

Informed Consent Statement: Not applicable.

Data Availability Statement: The data presented in this study are available on request from the corresponding author.

Conflicts of Interest: No potential conflict of interest was reported by the authors.

\section{References}

1. Mendling, W. Vaginal microbiota. Adv. Exp. Med. Biol. 2016, 902, 83-93. [PubMed]

2. Moosa, Y.; Kwon, D.; de Oliveira, T.; Wong, E.B. Determinants of vaginal microbiota composition. Front. Cell. Infect. Microbiol. 2020, 10, 467. [CrossRef] [PubMed]

3. Paladine, H.L.; Desai, U.A. Vaginitis: Diagnosis and treatment. Am. Fam. Physician 2018, 97, 321-329.

4. Redelinghuys, M.J.; Geldenhuys, J.; Jung, H.; Kock, M.M. Bacterial vaginosis: Current diagnostic avenues and future opportunities. Front. Cell. Infect. Microbiol. 2020, 10, 354. [CrossRef] [PubMed]

5. Muzny, C.A.; Blanchard, E.; Taylor, C.M.; Aaron, K.J.; Talluri, R.; Griswold, M.E.; Redden, D.T.; Luo, M.; Welsh, D.A.; Van Der Pol, W.J. Identification of key bacteria involved in the induction of incident bacterial vaginosis: A prospective study. J. Infect. Dis. 2018, 218, 966-978. [PubMed]

6. Jones, A. Bacterial Vaginosis: A review of treatment, recurrence, and disparities. J. Nurse Pract. 2019, 15, 420-423. [CrossRef] 
7. Kaambo, E.; Africa, C.; Chambuso, R.; Passomore, J.S. Vaginal microbiomes associated with aerobic vaginitis and bacterial vaginosis. Front. Public Health 2018, 6, 78. [CrossRef]

8. Kovachev, S. Defense factors of vaginal lactobacilli. Crit. Rev. Microbiol. 2018, 44, 31-39. [CrossRef]

9. Chen, X.; Lu, Y.; Chen, T.; Li, R. The female vaginal microbiome in health and bacterial vaginosis. Front. Cell. Infect. Microbiol. 2021, 11, 631972. [CrossRef] [PubMed]

10. Tachedjian, G.; Aldunate, M.; Bradshaw, C.S.; Cone, R.A. The role of lactic acid production by probiotic Lactobacillus species in vginal health. Res. Microbiol. 2017, 168, 782-792. [CrossRef] [PubMed]

11. Bastani, P.; Homayouni, A.; Ziyadi, S.; Tabrizian, V.G. Dairy probiotic foods and bacterial vaginosis: A review on mechanism of action. In Probiotics, ed EC Rigobelo; Intech Publishing: Rijeka, Croatia, 2012; pp. 445-456.

12. Reid, G.; Charbonneau, D.; Erb, J.; Kochanowski, B.; Beuerman, D.; Poehner, R.; Bruce, A.W. Oral use of Lactobacillus rhamnosus GR-1 and L. fermentum RC-14 significantly alters vaginal flora: Randomized, placebo-controlled trial in 64 healthy women. FEMS Microbiol. Immunol. 2003, 35, 131-134. [CrossRef]

13. Alberti, D.D.; Russo, R.; Terruzzi, F.; Nobile, V.; Ouwehand, A.C. Lactobacilli vaginal colonization after oral consumption of Respecta ${ }^{\circledR}$ complex: A randomized controlled pilot study. Arch. Gynecol. Obstet. 2015, 292, 861-867. [CrossRef] [PubMed]

14. Paek, N.S.; Lee, Y.Y.; Han, S.H.; Kang, C.H.; So, J.S. Characterization and inhibitory activity of Lactobacillus plantarum MG 989 and Lactobacillus fermentum MG901 isolated from vaginal microbiota of Korean women against Gardnerella vaginalis and Candida albicans. Korean Soc. Biotechnol. Bioeng. J. 2016, 31, 40-45.

15. Jung, Y.; Kang, C.H.; Shin, Y.J.; So, J.S. Characterization and antifungal activity against Candida albicans of vaginal Lactobacillus spp. isolated from Korean women. Korean Soc. Biotechnol. Bioeng. J. 2017, 32, 146-152.

16. Kang, C.H.; Kim, Y.G.; Han, S.H.; Kim, J.S.; Paek, N.S.; So, J.S. In vitro probiotic properties of vaginal Lactobacillus fermentum MG901 and Lactobacillus plantarum MG989 against Candia albicans. Eur. J. Obstet. Gynecol. Reprod. Biol. 2018, 228, $232-237$. [CrossRef] [PubMed]

17. Kang, C.H.; Han, S.H.; Kim, Y.G.; Paek, N.S.; So, J.S. In vitro probiotic properties of Lactobacillus salivarius MG242 isolated from human vagianl. Probiotics Antimicrob. Proteins 2018, 10, 343-349. [CrossRef]

18. Kim, Y.G.; Han, S.H.; Kim, J.S.; Jeong, Y.; Paek, N.S.; Kang, C.H. Probiotic properties and inhibitory activity of lactic acid bacteria isolated from vaginal microbiota of Korean women against Gardnerella vaginalis and Candia albicans. Korean Soc. Biotechnol. Bioeng. J. 2019, 34, 91-98.

19. Kim, H.; Kim, Y.G.; Kang, C.H. In vivo confirmation of the antimicrobial effect of probiotic candidates against Gardnerella vaginalis. Microorganisms 2021, 9, 1690. [CrossRef] [PubMed]

20. Won, G.; Choi, S.I.; Kang, C.H.; Kim, G.H. Lactiplantibacillus plantarum MG4296 and Lacticaseibacillus paracasei MG5012 ameliorates insulin resistance in palmitic acid-induced HepG2 cells and high fat diet-induced mice. Microorganisms 2021, 9, 1139. [CrossRef] [PubMed]

21. McGroarty, J.A.; Tomeczek, L.; Pond, D.G.; Reid, G.; Bruce, A.W. Hydrogen peroxide production by Lactobacillus species: Correlation with susceptibility to the spermicidal compound nonoxynol-9. J. Infect. Dis. 1992, 165, 1142-1144. [CrossRef]

22. Joo, H.M.; Hyun, Y.J.; Myoung, K.S.; Ahn, Y.T.; Lee, J.H.; Huh, C.S.; Han, M.J.; Kim, D.H. Lactobacillus johnsonii HY7042 ameliorates Gardnerella vaginalis-induced vaginosis by killing Gardnerella vaginalis and inhibiting NF- $\mathrm{kB}$ activation. Int. Immunopharmacol. 2011, 11, 1758-1765. [CrossRef]

23. Gilbert, N.M.; Lewis, W.G.; Lewis, A.L. Clinical features of bacterial vaginosis in a murine model of vaginal infection with Gardnerella vaginalis. PLoS One 2013, 8, e5959. [CrossRef] [PubMed]

24. Jang, S.E.; Jeong, J.J.; Choi, S.Y.; Kim, H.; Han, M.J.; Kim, D.H. Lactobacillus rhamnosus HN001 and Lactobacillus acidophilus GLa-14 attenuate Gardnerella vaginalis-infected bacterial vaginosis in mice. Nutrients 2017, 9, 531. [CrossRef]

25. Daniel, M.; Pascual, L.; Barberis, L. Curative effect of the probiotic strain Lactobacillus fermentum L23 in a murine model of vaginal infection by Gardnerella vaginalis. Lett. Appl. Microbiol. 2014, 59, 93-98. [CrossRef]

26. Sulin, C.; How, C.B.; Jamil, A.A.M.; Yih, C.S.; Meleh, H.U.; Lung, L.T.T. Characterisation of the probiotic qualities exhibited by Lactobacilli strains isolated from the anogenital tract. Malaysian J. Med. Health Sci. 2019, 15, 37-45.

27. Damke, E.; Tsuzuki, J.K.; Chassot, F.; Cortez, D.A.; Ferreira, I.C.; Mesquita, C.S.; da-Silva, V.R.; Svidzinski, T.I.; Consolaro, M.E. Spermicidal and anti-Trichomonas vaginalis activity of Brazilian Sapindus saponaria. BMC complement. med. ther. 2013, 13, 1-8. [CrossRef]

28. Shepherd, A.K.; Pottinger, P.S. Management of urinary tract infections in the era of increasing antimicrobial resistance. Med. Clin. North Am. 2013, 97, 737-757. [CrossRef] [PubMed]

29. Schwebke, J.R.; Muzny, C.A.; Josey, W.E. Role of Gardnerella vaginalis in the pathogenesis of bacterial vaginosis: A conceptual model. J. Infect. Dis. 2014, 210, 338-343. [CrossRef]

30. Morrill, S.; Gilbert, N.M.; Lewis, A.L. Gardnerella vaginalis as a cause of bacterial vaginosis: Appraisal of the evidence from in vivo models. Front. Cell. Infect. Microbiol. 2020, 10, 168. [CrossRef]

31. Gillor, O.; Nigro, L.M.; Riley, M.A. Genetically engineered bacteriocins and their potential as the next generation of antimicrobials. Curr. Pharm. Des. 2005, 11, 1067-1075. [CrossRef]

32. Macklaim, J.M.; Clemente, J.C.; Knight, R.; Gloor, G.B.; Reid, G. Changes in vaginal microbiota following antimicrobial and probiotic therapy. Microb. ecol. health dis. 2015, 26, 27799. [CrossRef] [PubMed] 
33. Soubhye, J.; Aldib, I.; Delporte, C.; Prévost, M.; Dufrasne, F.; Antwerpen, P.V. Myeloperoxidase as a target for the treatment of inflammatory syndromes: Mechanisms and structure activity relationships of inhibition. Curr. Med. Chem. 2016, 23, 3975-4008. [CrossRef]

34. Trifonova, R.T.; Bajpai, M.; Pasicznyk, J.; Chandra, N.; Doncel, G.F.; Fichorova, R.N. Biomarkers of leukocyte traffic and activation in the vagianl mucosa. Biomarkers 2007, 12, 608-622. [CrossRef]

35. Turovskiy, Y.; Noll, K.S.; Chikindas, M.L. The etiology of bacterial vaginosis. J. Appl. Microbiol. 2011, 110, 1105-1128. [CrossRef] [PubMed]

36. Chee, W.J.Y.; Chew, S.Y.; Than, L.T.L. Vaginal microbiota and the potential of Lactobacillus derivatives in maintaining vaginal health. Microb. Cell Fact. 2020, 19, 203. [CrossRef]

37. Homayouni, A.; Bastani, P.; Ziyadi, S.; Mohammad-Alizadeh-Charandabi, S.; Ghalibaf, M.; Mortazavian, A.M.; Mehrabany, E.V. Effects of Probiotics on the recurrence of bacterial vaginosis: A review. J. Low. Genit. Tract Dis. 2013, 18, 79-86. [CrossRef]

38. Bradshaw, C.S.; Morton, A.N.; Hocking, J.; Garland, S.M.; Morris, M.B.; Moss, L.M.; Horvath, L.B.; Kuzevska, I.; Fairley, C.K High recurrence rates of bacterial vaginosis over the course of 12 months after oral metronidazole therapy and factors associated with recurrence. J. Infect. Dis. 2006, 193, 1478-1486. [CrossRef]

39. Machado, A.; Cerca, N. Influence of biofilm formation by Gardnerella vaginalis and other anaerobes on bacterial vaginosis. J. Infect. Dis. 2015, 212, 1856-1861. [CrossRef]

40. Kumherová, M.; Veselá, K.; Kosová, M.; Mašata, J.; Horáčková, Š.; \& Šmidrkal, J. Novel potential probiotic Lactobacilli for prevention and treatment of vulvovaginal infections. Probiotics Antimicrob. Proteins 2021, 13, 163-172. [CrossRef] [PubMed]

41. Atassi, F.; Brassart, D.; Grob, P.; Graf, F.; Servin, A.L. Lactobacillus strains isolated from the vaginal microbiota of healthy women inhibit Prevotella bivia and Gardnerella vaginalis in coculture and cell culture. FEMS Immunol. Med. Microbiol. 2006, 48, 424-432. [CrossRef]

42. Sethi, S.; Das, A.; Sharma, M. Inhibition of Gardnerella vaginalis by lactobacilli. Int. J. Gynecol. Obstet. 2006, 93, 158-159. [CrossRef] [PubMed]

43. Atassi, F.; Servin, A.L. Individual and co-operative roles of lactic acid and hydrogen peroxide in the killing activity of enteric strain Lactobacillus johnsonii NCC933 and vaginal strain Lactobacillus gasseri KS120.1 against enteric, uropathogenic and vaginosisassociated pathogens. FEMS Microbiol. Lett. 2010, 304, 29-38. [PubMed]

44. Dover, S.E.; Aroutcheva, A.A.; Faro, S.; Chikindas, M.L. Natural antimicrobials and their role in vaginal health: A short review. Int. J. Probiotics Prebiotics 2008, 3, 219-230.

45. Bang, J.H.; Shin, H.J.; Choi, H.J.; Kim, D.W.; Ahn, C.S.; Jeong, Y.K.; Joo, W.H. Probiotic potential of Lactobacillus isolates. J. Life Sci. 2012, 22, 251-258. [CrossRef]

46. Martin, R.; Martin, C.; Escobedo, S.; Suarez, J.E.; Quiros, L.M. Surface glycosaminoglycans mediate adherence between HeLa cells and Lactobacillus salivarius Lv72. BMC Microbiol. 2013, 13, 210. [CrossRef] [PubMed]

47. Coudeyras, S.; Jugie, G.; Vermerie, M.; Forestier, C. Adhesion of human probiotic Lactobacillus rhamnosus to cervical and vaginal cells and interaction with vaginosis-associated pathogens. Infect. Dis. Obstet. Gynecol. 2008, 2008, 549640. [CrossRef]

48. Qian, Z.; Zhu, H.; Zhao, D.; Yang, P.; Gao, F.; Lu, C.; Lu, C.; Yin, Y.; Kan, S.; Chen, D. Probiotic Lactobacillus sp. strains inhibit growth, adhesion, biofilm formation, and gene expression of bacterial vaginosis-inducing Gardnerella vaginalis. Microorganisms 2021, 9, 728. [CrossRef] [PubMed]

49. Hardy, L.; Jespers, V.; Van den Bulck, M.; Buyze, J.; Mwambarangwe, L.; Musengamana, V.; Vaneechoutte, M.; Crucitti, T. The presence of the putative Gardnerella vaginalis sialidase A gene in vaginal specimens is associated with bacterial vaginosis biofilm PLoS One 2017, 12, e0172522. [CrossRef]

50. Giraldo, P.C.; de Carvalho, J.B.J.; do Amaral, R.L.G.; da Silveira Gonçalves, A.K.; Eleutério Jr, J.; Guimarães, F. Identification of immune cells by flow cytometry in vaginal lavages from women with vulvovaginitis and normal microbiota. Am. J. Reprod. Immunol. 2012, 67, 198-205. [CrossRef]

51. Mitchell, C.; Marrazzo, J. Bacterial vaginosis and the cervicovaginal immune response. Am. J. Reprod. Immunol. 2014, 71, 555-563. [CrossRef] [PubMed]

52. Cauci, S.; Culhane, J.F.; di Santolo, M.; McCollum, K. Among pregnant women with bacterial vaginosis, the hydrolytic enzymes sialidase and prolidase are positively associated with interleukin-1beta. Am. J. Obstet. Gynecol. 2008, 198, 132.e1-e7. [CrossRef]

53. Muzny, C.A.; Łaniewski, P.; Schwebke, J.R.; Herbst-Kralovetz, M.M. Host-vaginal microbiota interactions in the pathogenesis of bacterial vaginosis. Curr. Opin. Infect. Dis. 2020, 33, 59-65. [CrossRef] [PubMed]

54. Marrs, C.N.; Knobel, S.M.; Zhu, W.Q.; Sweet, S.D.; Chaudhry, A.R.; Alcendor, D.J. Evidence for Gardnerella vaginalis uptake and internalization by squamous vaginal epithelial cells: Implications for the pathogenesis of bacterial vaginosis. Microbes Infect. 2012, 14, 500-508. [CrossRef] [PubMed]

55. Hemalatha, R.; Ramalaxmi, B.A.; KrishnaSwetha, G.; Kumar, P.U.; Rao, D.M.; Balakrishna, N.; Annapurna, V. Cervico-vaginal inflammatory cytokines and sphingomyelinase in women with and without bacterial vaginosis. Am. J. Med. Sci. 2012, 344, 35-39. [CrossRef]

56. Wasiela, M.; Krzemiński, Z.; Kalinka, J.; Brzezińska-Błaszczyk, E. Correlation between levels of selected cytokines in cervicovaginal fluid of women with abnormal vaginal bacterial flora. Med Dosw Mikrobiol. 2005, 57, 327-333. [PubMed] 
57. Santos, C.M.A.; Pires, M.C.V.; Leão, T.L.; Silva, A.K.S.; Miranda, L.S.; Martins, F.S.; Silva, A.M.; Nicoli, J.R. Anti-inflammatory effect of two Lactobacillus strains during infection with Gardnerella vaginalis and Candida albicans in a HeLa cell culture model. Microbiology 2018, 164, 349-358. [CrossRef]

58. Swidsinski, A.; Mendling, W.; Loening-Baucke, V.; Ladhoff, A.; Swidsinski, S.; Hale, L.P.; Lochs, H. Adherent biofilms in bacterial vaginosis. Obstet. Gynecol. 2005, 106, 1013-1023. [CrossRef] [PubMed] 